\title{
La Malinche, una Eva indígena: asociaciones misóginas y subversiones simbólicas
}

\author{
La Malinche, An Indigenous Eva: Misogynistic \\ Associations and Symbolic Subversions
}

\section{RESUMEN}

Hay mujeres, como la Malinche, Lilith, Eva, que, más allá de su componente histórico, desde una mirada más simbólica son también ejemplos desde los que descubrir los recorridos de la misoginia y su presencia en asociaciones comunes arraigadas en los imaginarios populares. En este artículo, recordaremos primero las representaciones de lo femenino asociadas a Lilith y Eva (frente a su antítesis: la Virgen María) para, después, gracias a estas inspiraciones, repensar la figura de la Malinche, en cuyo nombre y mito está inscrita una visión misógina que se ha ido imponiendo poderosamente. A pesar de ello, al igual que otros recorridos de la misoginia, el mito de la Malinche no ha borrado del todo las huellas simbólicas que dejan abierto el camino de su subversión.

Palabras clave: Malinche, Eva, Lilith, imaginarios misóginos, México.

\section{Abstract}

There are women, such as Malinche, Lilith, Eva, who, beyond their historical component, from a more symbolic perspective, are also examples to discover the paths of misogyny and its presence in common associations rooted in popular imagery. In this article, we will first recall the representations of the feminine associated with Lilith and Eva (versus their antithesis: Virgin Mary), and then, thanks to these inspirations, rethink the figure of Malinche, in whose name and myth it is inscribed a misogynistic vision that has been powerfully imposed. Despite this, like other developments of misogyny, the Malinche myth has not completely erased the symbolic traces that leave the way of its subversion open.

Keywords: Malinche, Eva, Lilith, misogynist imaginaries, Mexico.

\section{SUMARIO}

1.- Introducción. 2.- Inspiraciones: Lilith la insurrecta y Eva la desobediente. 3.- La Malinche, mujer «lengua» de los muchos nombres. 4.- Conclusiones. -Bibliografía. 


\section{Introducción}

Todo está guardado en la memoria, sueño de la vida y de la historia.

La memoria pincha hasta sangrar a los pueblos que la amarran y no la dejan andar libre como el viento.

León Gieco

Mujeres temibles, seres inquietantes y amenazantes: así aparecen la temeraria Lilith, la irreverente Eva, la traidora e inteligente Malinche. Frente a ella, la abnegada y dulce María, paradigma de ternura, abnegación y sacrificio. Los cuerpos femeninos sexuados, representados por las figuras de Lilith y Eva, se erigirán a emblema de la mujer pecadora, hechicera, bruja, maga y tentadora. $\mathrm{O}$, según las latitudes, asumirán otro semblante, como en la mexicana Malinche.

En la interpretación de Casanova y Larumbe (2005: 56), la evolución de los primeros grupos humanos en clanes, en tribus, en formas de organización social más compleja, habría constituido terreno fértil para la instauración progresiva y persistente de un discurso de dominación y exclusión de las mujeres que, andando el tiempo, devendrá en sistema patriarcal, legitimando el ejercicio del poder sustentado en las diferencias biológicas. Ello iría asociado con odio y temor hacia a las mujeres como seres distintos por su cercanía con la naturaleza a través de la reproducción y crianza de los hijos expresado en figuras de lo femenino con claras implicaciones represivas de los mitos femeninos (castigos ligados al carácter sexual y reducción a la función reproductora como consecuencia de la transgresión femenina). Los elementos de esta construcción se fueron sedimentando y pueden aparecer en el discurso como si hubieran estado siempre presentes, si bien el análisis revela su historicidad (su relación con un momento histórico concreto): por ejemplo, la asociación entre la serpiente, el pecado y la naturaleza femenina, que se deba a la edad media, pero que aparece como si estuviera desde «el origen de los tiempos» o desde «un tiempo inmemorial». Y es que estas representaciones pertenecen al mito más que a la historia: surgen, cambian, se resignifican, pero no desaparecen (Girard, 1982: 58-63) y, al mismo tiempo, se usan como si siempre hubieran permanecido iguales.

Aquí, nuestro interés se centra en los mitos relacionados con la representación del femenino y, concretamente, en las asociaciones misóginas presentes en la figura de la Malinche. La misoginia, como categoría de análisis, se enmarca no sólo dentro de las discusiones académicas, sino también es resultado de la aportación del feminismo y de los movimientos reivindicativos de las mujeres, que pretendían explicar las causas de las relaciones asimétricas entre los hombres y mujeres dentro del sistema patriarcal en la sociedad contemporánea (Bosch et al., 1999: 79). En estas perspectivas, la misoginia es entendida como una construcción ideológica que plantea la dominación del hombre y la subordinación de la mujer sustentada en tres argumentos principales: la mujer es inferior al hombre biológicamente; inte- 
lectualmente, limitada en su inteligencia por razones naturales, y moralmente, de acuerdo con el paradigma de Eva (Moreno, 1998: 179).

En este artículo, asumimos como punto de partida la necesidad de plantear la historicidad de las construcciones de las representaciones del femenino, pero nuestro objetivo principal es repensar la figura de la Malinche, en cuyo nombre y mito está inscrita una visión misógina que se ha ido imponiendo poderosamente en el imaginario popular mexicano, gracias también a su estrecha relación con el debate acerca de la identidad nacional, su definición y defensa. Este mito negativo, de manera parecida a lo ocurrido con las figuras de Lilith y Eva, ha surgido y ha sido periódicamente adaptado en distintos tiempos históricos que mantienen su fuerza en una visión misógina que aparece sin solución de continuidad, si bien es posible desvelar sus recorridos.

Nos proponemos, en primer lugar, recordar las principales representaciones misóginas del femenino asociadas a las figuras de Lilith y Eva. Estas asociaciones misóginas nos servirán de inspiración para revisar, a continuación, el mito negativo de la Malinche, enfatizando los recorridos de esta construcción, más reciente de los que pudiera pensarse, así como los caminos alternativos que permiten su subversión.

\section{Inspiraciones: Lilith la insurrecta y Eva la desobediente}

En el mito comparece no lo puramente sucedido, sino lo pensado. De modo que en lugar de la verdad externa aparece la verdad interna y, en vez de los hechos, aparecen hechuras del espíritu.

Heinrich, 1975: 75

Mujeres rebeldes, maldecidas y peligrosas que se salen de la norma y el «deber ser» femenino, impuesto por los hombres, como Lilith, Eva y la Malinche. Genuinamente desobedientes e insurrectas, como la sensual Lilith, que no se sometió a tener relaciones sexuales en posición horizontal y debajo de su amante Adán. La falta de sumisión y de acuerdo frente a esta forma de tener encuentros sexuales, a la larga, conducirán a Lilith a elegir abandonar a Adán antes que someterse y renunciar a la igualdad (Graves y Patai, 1986: 59).

Bornay recuerda que en la tradición hebrea del Talmud, Lilith aparece como la primera pareja de Adán anterior a Eva, «pero que Dios no formó de la costilla del primer hombre, sino de «inmundicia y sedimentos»» (1990: 25-29). Por su parte, los textos asirios la representan como «una seductora y devoradora de hombres, a los cuales atacaba cuando estaban dormidos. Espíritu maligno que atacaba a las parturientas y a los recién nacidos» (Bornay, 1990: 35). Habría sido la influencia de las interpretaciones asirias la responsable de esta profunda alteración en la iconografía de Lilith, cuyas primeras referencias en las tablillas sumerias, bajo la denominación de Lilitu o Lamatsu, remitían más bien al carácter guiador hacia la sabiduría y la inmortalidad de este «espíritu del viento nocturno». Obviando su vinculación con los ritos sexuales asociados al culto de la diosa Ishtar y su proyección como protectora de la fertilidad del mito sumerio, en la iconografía asiria Lilith pasa a ser representada como una figura demoniaca. Ese proceso culminará con la visión monstruosa 
del Talmud y los escritos bíblicos (Beteta, 2016: 74-78). En el imaginario, Lilith aparece como una mujer de larga cabellera, o también desnuda, con terminación de cola de serpiente (Bornay, 1990: 58) en sustitución de sus pies, o bien alada viajando por los aires, «a su aire». Pero, sobre todo, lo que permanecerá es el resultado de esa transformación y redefinición simbólica, que se afianzará en una imagen negativa, que acentuará la vertiente sexual. En el Zohar, obra principal de la Cábala, se la considera como la ramera, la perversa, la falsa e incluso la negra (Bornay, 1990: 67).

La adopción de la figura de Lilith por la tradición rabínica y su consideración como la primera mujer de Adán antes de la creación de Eva deja, sin embargo, también otra huella simbólica: la de la rebeldía, con la negativa de Lilith de situarse bajo el dominio masculino y su huida. Reemplazada por Eva, será esta última (la Eva bíblica) la que irá asumiendo más importancia, en la representación misógina de las mujeres, como modelo de feminidad transgresora, sobre todo gracias al discurso edificado a lo largo de la Edad Media sobre la idea del pecado original.

Entrada triunfal la de Eva, de ser un cuerpo fragmentario, hecho de la costilla de Adán, que representa la existencia del mal, encarnado en el cuerpo femenino.

Eva, figura bíblica y con el paso de los años mítica, responsable de brindar a la humanidad la posibilidad del saber y del discernimiento, la astuta y atrevida Eva Mujer símbolo del mal, "puerta del infierno", de la astucia, de la justicia social y familiar, dadora de vida y de remedios para curar los males del cuerpo y del alma, sensual, provocadora, de belleza fascinante y seductora. Comer del fruto prohibido la coloca en el espacio del mal, pero también del discernimiento y de la fuerza de voluntad capaz de seducir y convencer a Adán de la poderosa y trascendente decisión de convertir a los hombres y mujeres en seres autónomos, libres, contradictorios, ambiciosos de saber, de poder, capaces de construir clanes, tribus, sociedades antiguas, modernas y postmodernas. Eva precipita al hombre al abismo de la sabiduría y la libertad. Acto inaugural del destino y estigma de la mujer, hasta nuestros días (Avalos, 2005: 87-88).

En génesis, la insolente subversión de Eva será castigada, al ser la mujer la causa del pecado. El mito de la Eva bíblica se usará así como referente simbólico de construcciones ideológicas que reducirán a las mujeres a su función reproductora, incapacitándolas para el acceso a la sabiduría.

La irreverente Eva, la rebelde y curiosa, primera mujer pecadora sobre la tierra de la mítica historia de la creación divina, pecó y sedujo al ingenuo Adán hacia lo prohibido y el acto de pensar. Instalando con este acto el libre albedrío para toda la humanidad, sin olvidar que justo aquí, en tiempos muy antiguos, las mujeres serán percibidas dentro del imaginario colectivo como seres esencialmente distintos, que se fundían con la naturaleza y con la carne, que atraían, pero atemorizaba. Del atrevimiento de Eva por probar el fruto prohibido deviene el castigo eterno a su condición de mujer: por extensión todas las mujeres pueden ser percibidas diferentes y peligrosas, hijas de Eva, como, también, hijas de Lilith, en un continuum de representación de la mujer en la que la sabiduría femenina, asociada a lo monstruoso y a lo malvado, es merecedora de ser reprimida y castigada 
Las implicaciones represivas de la imagen de Lilith y Eva son todavía más evidentes con el consolidarse de una división maniquea de dos modelos de feminidad: Lilith y sobe todo Eva, la rebelde y desobediente, quedarán como el paradigma de la «mujer mala» frente a su antítesis, la «mujer buena», la maternal, la pura, la sumisa, asociada a la figura de la Virgen María. El culto mariano se consolidará en época relativamente reciente, teniendo su apogeo en el siglo XIII, época en la que también se establecerá de forma definitiva esta dicotomía: «La Iglesia medieval adorará y glorificará a María porque ella es, en realidad, la santa, la mujer desexualizada que concibió sin pecado, en oposición a Eva, de la cual la mujer común es hija» (Bornay, 1990: 32). Sin embargo, nuestra actual percepción visual de Eva, de Lilith y de María es deudora sobre todo de la iconografía misógina de finales del siglo XIX, cuando se desarrolla el arquetipo de la femme fatale, objeto del mencionado estudio de Bornay.

En un lugar como México, parte de ese «otro» o «extremo» Occidente que es América Latina (Carmagnani, 2004; Rouquie, 1989), estos imaginarios, representaciones y figuras del femenino asociadas a Lilith, Eva y María, -con sus profundas influencias en la moral, los temores y los deseos y, también, con su potencial subversivo- han confluido con otras tradiciones, especialmente con las indígenas prehispánicas. Así las mexicanas, hijas de Lilith, de Eva y de María, somos también hijas de Xochiquetzal, diosa de la sensualidad y el erotismo, y de Guadalupe-Tonatzin, por la sensibilidad y la magia, por la dulzura, por el sustrato sanador, por la capacidad de sororidad, de consuelo frente al nacimiento, la enfermedad, la muerte y las tragedias humanas. Y también de sor Juana Inés de la Cruz, hijas nacidas de su pluma fecunda, de su imaginación y de su denuncia de la misoginia colonial. Pero, si hay una figura que se eleva preponderante, es Malinalli, como la llamaban sus contemporáneos indígenas, o doña Marina, como la llamaban sus contemporáneos españoles. Más conocida por un nombre que fue adquiriendo connotaciones despectivas como resultado de uno de los recorridos de la misoginia: la Malinche.

\section{La Malinche: mujer «lengua» de los muchos nombres}

Primero fue el viento. Más tarde como un relámpago, como una lengua de plata en el cielo, fue anunciada en el Valle del Anáhuac la tormenta que lavaría la sangre de la piedra. Después de que el agua habló, un gran silencio, lo rompió el llanto de una niña a quien nombraron Malinalli.

Esquivel, 2006: 2

Antes de su transformación en la Malinche, fue conocida y reconocida como «lengua» (interprete), de hecho, se convirtió en la principal lengua de Hernán Cortes, suplantando a Jerónimo de Aguilar.

La historia y los recorridos de sus nombres (Malinalli, doña Marina, Malintzin, Malinche) dan cuenta de los usos simbólicos (sincrónicos y diacrónicos) de esta figura y de su transformación en mito. Todos estos nombres no desaparecieron, ni lo hicieron los significados que se les fueron asociando, a pesar de que el mito de la Malinche se fue imponiendo poderosamente, dejando así abiertas también 
otras elecciones y otras posibilidades de interpretación (Grillo, 2011; Hoppe, 2011; Roldan Rueda, 2012).

Aquí, nuestro objetivo no es reconstruir hechos y procesos históricos, sino repensar los caminos del mito y desvelar sus recorridos misóginos: Malinalli, con todos sus nombres, no solo es historia, sino también memoria y, en la medida en que es memoria, también es mito e incluso metáfora arraigada en la cultura popular. Así, la figura de la Malinche es metáfora de la traición a la patria como en el corrido «La maldición de Malinche» de Gabino Palomares, compuesto en 1975 (Roldán, 2012: 1-2).

Los usos contemporáneos, sin embargo, no han cancelado del todo las huellas de usos más antiguos. En la época de la conquista, para los españoles, como recuerda Grillo (2011: 16), «en un principio Malinche fue Cortés -el Malinche, no la Malinche», de la misma manera en que para los indígenas era «Malinalli-tzin» (el señor de Malinalli). Ello se puede repensar en clave feminista, recuperando una visión positiva, activa e incluso poderosa: «Para los indígenas ellas es definitivamente la dueña del discurso y él, Cortés, el Capitán Malinche, jefe de los españoles, un hombre despojado de repente de su virilidad» (Glantz, 2006).

Durante la colonia, es una figura positiva y apreciada, con un rol activo en la conquista. Y esta es la imagen que difunde Bernal Díaz del Castillo. ${ }^{2}$ La anuncia de manera caballeresca y solemne, nos dice que nació primogénita de una noble familia nahua de la región de Painala, afirma que después de la muerte de su padre la madre casó con otro hombre, con el cual tuvo un hijo varón, y que para conservar la herencia de este los padres vendieron a la hija a un matrimonio de mercaderes: «Dieron de noche a la niña Doña Marina a unos indios de Xicalango le dieron a los de Tabasco y los de Tabasco a Cortés» (Díaz del Castillo, 1984: 85). Esto sucedió después de la batalla de Centla como un regalo a los españoles junto con otras 19 esclavas. Los objetos de oro y otros presentes «no fue nada en comparación con las veinte mujeres y entre ellas una muy excelente mujer, que se dijo Doña Marina, que así se llamó después de vuelta cristiana» (Díaz del Castillo, 1984: 87). ${ }^{3}$ Nos dice Gómara que estas mujeres, Marina y sus compañeras, fueron las primeras cristianas bautizadas en toda la Nueva España (López de Gómara, 1986: 358).

Díaz del Castillo la describe con cierta deferencia, como no lo haría con ninguna otra mujer: «e luego la bautizaron, y se puso por nombre Doña Marina aquella india y señora que allí nos dieron, de pueblos y vasallos. Y esa Doña Marina tenía mucho ser y mandaba absolutamente entre los indios» (Díaz del Castillo, 1984: 159). También afirma que «era de buen parecer y entremetida e desenvuelta»: de buen parecer, posiblemente que era atractiva, al decir entremetida, que se relacio-

2 Díaz del Castillo escribe su relato de la Conquista al final de su vida y como refutación de la obra de Francisco López de Gómara, cronista oficial de la Corte. A diferencia de Gómara, que nunca estuvo en el Nuevo Mundo y escribe basándose en las cartas de Cortés y lo narrado por otros, Díaz del Castillo participó directamente en los eventos y conoció personalmente a Doña Marina, algo que recuerda reiteradamente en su crónica.

3 Regalar mujeres en el mundo prehispánico constituía una forma de establecer alianzas políticas, de dar la bienvenida a los guerreros, de pactar la paz después de una guerra o de establecer relaciones familiares (Palerm, 1949: 231-278). 
naba con los hombres, los caciques, los conquistadores, los sacerdotes indígenas, hombres todos con los que trataba para acercar a Cortés a ellos y a su manera de pensar y seguramente a sus intenciones. En situaciones de tratos con los caciques, ella está presente como traductora, pero también como partícipe de las grandes y pequeñas decisiones de Cortés y sus asuntos políticos. Fue a través de ella que él pudo descifrar el mundo posible de su conquista y futura gloria, le mostró secretos, rivalidades, magias, rituales, costumbres, creencias, fracturas, temores de los pueblos indígenas.

Pondera Díaz del Castillo que su presencia fue fundamental para conocer a Tenochtitlan, demás territorios indígenas y para la conquista: «fue gran principio para nuestra conquista, he querido declarar esto, porque sin Doña Marina no podíamos entender la lengua de la Nueva España y de México» (Díaz del Castillo, 1984: 159). Malintzin hablaba maya y náhuatl, le traducía a Jerónimo de Aguilar del náhuatl al maya y este del maya al castellano a Cortés. El propio Díaz del Castillo recuerda reiteradas ocasiones en las que le nombran Malinche a Cortés. Este hombre, el conquistador, en la sociedad indígena patriarcal adquiere identidad al ubicarlo con una mujer indígena, su compañera y traductora, durante su empresa de conquista, especialmente con los tlaxcaltecas, cuando le trajeron presentes e hicieron alianzas. Para ello, le llevaron los principales y caciques a sus hijas y sobrinas para sellar la alianza política en contra de los mexicas, y se dirigen a él, diciéndole: «Malinche [Cortés], porque más claramente conozcáis el bien que os queremos y deseamos en todo contentaros, nosotros os queremos dar a nuestras hijas para que sean vuestras mujeres y hagáis generación» (Díaz del Castillo, 1984: 268).

Así, Díaz del Castillo, con respeto y admiración, afirma rotundamente que «fue tan excelente mujer y buena lengua» y «por esta causa siempre la traía Cortés consigo» (Díaz del Castillo, 1984: 83). Algo que se confirma en la narración de López de Gómara, cuando rememora que Cortés le confesó la confianza que le tenía, «ella sola junto con Jerónimo de Aguilar fueron nuestras verdaderas lenguas entre los nuestros y los de aquella tierra», y la fundamental importancia de su papel de intérprete, al mencionarle que «tenía un seguro y leal faraute en aquella esclava junto con Aguilar» (López de Gómara, 1986: 358). Lo cierto es que Hernán Cortés, en todos los eventos al momento de conocer y entrevistarse con los principales, hacer alianzas políticas con los enemigos de los aztecas, identificar a los adversarios de los mexicas, se enteró por Marina, situación que capitalizaría para enfrentarlos entre sí y obtener aliados indígenas. La Malinche aparecerá en todos sus asuntos, tales como hablarle de su lealtad al rey Carlos de Austria, emperador de los cristianos, de su devoción a la Virgen, así como comer juntos, tener relaciones sexuales con ella, como su eterna e inseparable «lengua», amante, compañera, en toda su empresa de conquista en tierras mesoamericanas. Situación que la hace acreedora de que el ilustre caballero Cortés le gestione la Carta de Probanzas y Méritos frente a la Corona.

Además de una figura positiva, Malinalli/Doña Marina no parece haber sido considerada entonces un personaje «siempre pasivo» como afirma Grillo (2011: 19). Su representación pictográfica en el siglo XVI es la de una mujer poderosa y elegante y, en las piezas teatrales de esa época, ella y Cortés aparece como figuras 
heroicas del triunfo de la cristiandad (Karttunen, 1997). Hubo incluso una versión milagrosa, la que difundió Fernando de Alva Ixlilxóchitl, en la que Malinalli/Doña Marina es retratada como un don providencial para la cristianización.

Es en una época posterior, en el siglo XIX, después de la independencia, cuando esa imagen positiva de las crónicas coloniales se va transformando, las cualidades de la mujer lengua se convierten en sus opuestos y su figura empieza a difundirse como el paradigma de la traición, incluso apelando a las mismas fuentes que la elogiaron, como la crónica de Bernal Díaz del Castillo (González, 2002: 43). Es ese el momento histórico en el que se va forjando un imaginario que consagró a la Malinche como la antiheroína nacional (Spinoso, 2012).

El discurso gestado por los liberales a mediados del siglo XIX (Brading, 1973:120) -en su búsqueda de una identidad nacional que afianzara la emergencia del Estado-nación- encuentra en la Malinche la culpable perfecta, origen y causa de los males acarreados por la conquista. Su representación positiva es reemplazada por la de una «Eva mexicana» (Messinger, 1991: 9). Lo que, por otra parte, crea una paradoja difícil de asimilar, ya que esa otra, la culpable, es también la madre simbólica de los mestizos, la mujer indígena que «favoreció» la conquista a través del conocimiento de varias lenguas y al servir de intérprete a Cortés.

Es entonces, en el siglo XIX, cuando se crea y difunde una nueva narración acerca de la Conquista (González, 2002: 89-98) y del papel de Malinalli/Doña Marina/ Malintzin, dando así el paso de su conversión definitiva de personaje histórico a uno simbólico. De manera especular al papel representado por la figura divina y mítica de la Guadalupe (la versión nativa de la Virgen María, asociada a la diosa azteca Tonatzin), «la esclava indígena Malintzin Tenepal fue transformada en el doble monstruoso de Guadalupe» (Alarcón, 1993: 20).

Si en la historiografía del siglo XIX todavía podemos encontrar un juicio positivo (incluso su reificación como heroína, como en la conocida obra de William H. Prescott), es en las novelas -especialmente en Xicotencatl de 1826, donde mejor se afianza el mito negativo de la Malinche, si bien también hay novelas donde la que prevalece es su imagen de victima (Grillo, 2011: 19-21). En ambos casos, ya se va perdiendo aquella figura importante, poderosa y digna de elogios que se había asociado con ella.

En el siglo XX, de nuevo se resignifican sus muchos nombres: el movimiento indigenista recupera el nombre indígena (Malinalli) y los promotores del mestizaje usan Malintzin por ser sincrético y no excluyente (como Antonio Peñafiel los primeros años del siglo). Así, se realza tanto la figura positiva, en la exaltación de madre de la patria, como la negativa, en la traición, algo que va adquiriendo un nombre propio asociado a la Malinche. Surge así el malinchismo como concepción simbólica negativa de la nacionalidad (Núñez, 2019: 12) aludiendo a la amante de Hernán Cortés como la primera mujer traidora de tiempos antiguos que favoreció la conquista y el derrocamiento del Imperio azteca. Mientras se consolida el culto a Cuauhtémoc como paradigma heroico de la mexicanidad, también se construye el arquetipo de la traición y de la anti mexicanidad representado por esa mujer indígena que había sido «lengua». 
Es la obra de Octavio Paz (1950), la que consagra al malinchismo como sumisión y violencia, entrega y violación. El elemento sexual adquiere protagonismo: la «Chingada», representación de la madre violada, es asociada a la Conquista, entendida como violación histórica y como violación de las mujeres indígenas. Y la figura simbólica de esta «entrega» (no importa si fue seducida o violada) es, para Paz, la Malinche. Allí parecería concluirse el recorrido de la mujer lengua, con ese nombre (Malinche) y ese significado e imagen negativa, prototipo de la traición femenina, con un profundo arraigo en el imaginario popular mexicano.

A pesar de ello, las huellas de sus nombres y de sus figuras anteriores quedaron de alguna manera presentes, para recobrar vida y resignificarse desde otras perspectivas. Así, la narrativa latinoamericana contemporánea reescribe y revisa el mito de la Malinche (Hoppe, 2011; Tate, 2019). Y así, la influencia y difusión de El laberinto de la soledad provoca la adopción de la Malinche por el feminismo chicano, reapropiándose positivamente de un nombre que se le había asignado con acepción negativa (Zinam y Molina, 1991; Alarcón, 1993: 33-48; Tate, 2017: 84-85). Las escritoras feministas chicanas se reivindican así orgullosamente como «hijas simbólicas de la Malinche» (Messinger, 1991: 142), recuperando una visión maternal positiva y resaltando el paralelismo entre su propia experiencia vital y la de una mujer subalterna plurilingüe que vivió entre dos culturas. Así, también, en un sentido más general, el mito negativo se puede convertir en símbolo positivo de hibridez y multiculturalismo (Franco, 1996), recuperando ese significado que ya advertía Todorov, en su conocida obra (1987), donde la hace aparecer como la encarnación de la alteridad y de la mezcla.

\section{Conclusiones}

Malinchismo.

De Malinche, esclava mexica que desempeñó un papel importante en la conquista española de México como intérprete, consejera y amante de Hernán Cortés, e -ismo. Actitud de quien muestra apego a lo extranjero con menosprecio de lo propio.

(RAE, 2014)

De manera parecida a lo ocurrido con las figuras de Lilith y Eva, y sus transformaciones y re-significaciones en clave misógina, el mito negativo de la Malinche se ha arraigado en el imaginario mexicano como si existiera desde tiempos inmemoriales. Incluso, ha dado origen a un neologismo («malinchismo») frecuentemente usado en el lenguaje común. Y, sin embargo, sabemos que este mito es relativamente reciente, habiendo surgido en el siglo XIX y adquiriendo sus peores matices -con la referencia explícita a la violencia sexual- a mediados del siglo XX.

Descubrir y recordar su historicidad -al mismo tiempo en que se recuperan sus significados más antiguos o se proponen interpretaciones inéditas- permite también reconocer que el mito de la Malinche es parte de la acción de «naturalizar» lo que es en realidad una construcción discursiva y de poder, que presenta la domina- 
ción masculina como una ley natural (Bourdieu, 1998: 35). Es un mito funcional a la reproducción de las relaciones de dominación y de las desigualdades que perpetúan el orden establecido. Un orden en el que son fundamentales tanto la violencia simbólica como el esquema binario de clasificaciones arbitrarias, en el que también se inscribe la dualidad masculino-femenina (Bourdieu, 1998: 20) ${ }^{4}$.

En los mitos de Lilith, Eva y la Malinche opera además otra dualidad, esta vez interna a la representación de lo femenino: la «mujer mala» frente a su antítesis, la «mujer buena». Lo monstruoso, lo malvado y lo pecaminoso frente a lo puro y a lo maternal. Así la Lilith de la interpretación asiria y de la tradición rabínica y la bíblica Eva recorren el imaginario masculino durante siglos. La Virgen sirve, en el mismo relato, de contrapunto oportuno para completar esta narrativa. Y todo ello irrumpe en la América conquistada durante el siglo XVI, donde Malinalli, llamada Doña Marina por los españoles, será la protagonista de otro recorrido misógino que la transformará en la figura de la Malinche, la traidora y prototipo de la traición femenina, al mismo tiempo víctima y culpable de su propia entrega y violación (simbólica y sexual) y metáfora de la violación histórica (la Conquista) y de la violación de las mujeres indígenas. La confluencia con la leyenda de la Llorona -un paralelismo más con la figura de Lilith e, incluso la de Eva y de la mítica Medea ${ }^{5}$ refuerza aún más su visión negativa como madre simbólica de la nación mexicana. En la equivalencia Malinche/Llorona, los motivos de su deambular nocturno y eterno son la traición y el pecado carnal, los elementos principales de un antimodelo femenino. Así, desde el mito, estas asociaciones se extienden no sólo a la interpretación del pasado nacional, sino al juicio moral acerca de las mexicanas contemporáneas, especialmente de las indígenas, fundado en una idea de traición femenina en la que son al mismo tiempo víctimas y culpables.

En el abarrotado campo de representaciones que se ha ido configurando alrededor de Malinalli/Doña Marina/Malinche, sin embargo, todos estos elementos, como se ha ido mostrando, pueden ser subvertidos, abriendo camino para otras lecturas e interpretaciones. En ellas, se puede volver a los nombres más antiguos, recuperando su papel de «mujer lengua», poseedora de la palabra creadora, que le permitió trascender a protagonista de uneventos extraordinario, que impactó y cambió al mundo europeo y americano, una mujer que fue capaz de posicionarse

4 En sus «apuntes», Posada (2017) señala la escasa atención de Bourdieu a las obras feministas, si bien reconoce que su propuesta permite una reconsideración de las relaciones entre los sexos y de allí que sean de interés para una perspectiva crítico-feminista.

5 La leyenda tiene muchas versiones (y no solo en México), pero en general suele aparecer el espíritu de una madre que ahogó a sus hijos, y ahora está destinada a pasar la eternidad buscándolos en los ríos y en los lagos. Se trataría más bien de una familia de leyendas que puede adscribirse a la categoría folclórica de «espantos» (Martos, 2015), si bien lo que interesa aquí es su asociación con varias diosas mexicas (sobre todo con Cihuacóatl) y su superposición con la Malinche, que volvería arrepentida a llorar por su traición a los indígenas. Lo mismo que puede asociarse con la versión monstruosa de Lilith como espíritu maligno que ataca a las parturientas y a los recién nacidos, y con el pecado original de Eva y la culpa congénita de la mujer. Además, Ignacio Manuel Altamirano, en sus crónicas teatrales de 1875, asimilaba Medea con la Malinche y la Llorona. La asociación Malinche/Llorona se retomará también en el librito didáctico que José María Marroquí publicó en 1887 (Spinoso, 2012). 
como Doña Marina, dueña de la palabra, personaje que logra reconocimiento y un lugar destacado en las crónicas. Estas lecturas también permiten seguir desmontando el mito de la Malinche, devolviéndole su historicidad, desvelando el momento en el que el personaje histórico cede definitivamente el paso al personaje simbólico y analizando la progresiva adquisición de elementos negativos que van definiendo un poderoso recorrido misógino y estigmatizador, dejando una profunda herencia a la mujeres mexicanas.

Hoy todas las mexicanas somos malinches, la que reivindica su ser indígena, la que tiene el piercing, la que lleva tatuajes sobre su piel, la que estudia, el ama de casa, la que trabaja en la fábrica o en la oficina, la que es maestra, la enfermera, la sirvienta o la arquitecta, la divorciada, la madre soltera, la que es prostituida. Es la mujer mexicana contemporánea que desafía el orden patriarcal con su actitud, su presencia y, sobre todo, su palabra.

\section{Bibliografía}

Alarcón, Norma (1993). «Traduttora, Traditora: una figura paradigmática del feminismo de las chicanas», en Debate Feminista, pp. 19-48.

Arana, María José (2010). Eva y Pandora: "por causa de ellas todos morimos», Sevilla: ArCiBel Editores.

Archer, Robert (2001). Misoginia y defensa de las mujeres: antología de textos medievales, Madrid: Ediciones Cátedra.

Avalos, Antonia (2005). «La mujer galante y la moral durante el porfiriato en el Puerto de Veracruz» en Rubio, María Amalia, Espacios de género, México: Universidad Autónoma de Aguascalientes, pp. 57-96.

BARING, Anne (1991). El mito de la diosa. Evolución de una imagen, Barcelona: Ediciones Siruela.

Bennassar, Bartolomé (2002). Hernán Cortés: El conquistador de lo Imposible, Madison: Universidad de Wisconsin.

Bernabé, Carmen (1994). María Magdalena. Tradiciones en el cristianismo primitivo, Estella: Verbo Divino.

Beteta MARTín, Yolanda (2016). Brujas, femme fatale y mujeres fálicas. Un estudio sobre el concepto de monstruosidad femenina en la demonología medieval y su representación iconográfica en la Modernidad desde la perspectiva de la Antropología de Género. Tesis Doctoral, Universidad Complutense de Madrid.

Bornay, Erika (1988). Las hijas de Lilith, Madrid: Ediciones Cátedra.

Bosch, Esperanza et al. (1999). Historia de la misoginia, Barcelona: Anthropos.

Bourdieu, Pierre (1998). La dominación masculina, Madrid: Paidós.

Brading, David (1973). Los Orígenes del Nacionalismo Mexicano, México: Ediciones ERA, 2004, 10a edición.

Carmagnani, Marcello (2004). El otro Occidente. América Latina desde la invasión europea hasta la globalización, México: Fondo de Cultura Económica.

CASAnova, Eudaldo y María Ángeles LARumbe Gorraitz (2005). La serpiente vencida. Sobre los orígenes de la misoginia en lo sobrenatural, Zaragoza: Prensas Universitarias de Zaragoza. 
Cóndova, Arnaldo (1973). La ideología de la Revolución Mexicana, Ediciones Era, México.

Díaz del CAstillo, Bernal (1984). Historia verdadera de la conquista. Tomo A, Madrid: Historia 16, edición de Miguel León-Portilla.

DURAND, Gilbert (1982). Las estructuras antropológicas de lo imaginario, Madrid: Taurus. Esquivel, Laura (2006). Malinche, México: Editorial Suma de Letras, 2015.

Figes, Eva (1972). Actitudes patriarcales: las mujeres en la sociedad, Madrid: Alianza Editorial. FrANCO, Jean (1996). «La Malinche: del don al contrato sexual» en Marcar diferencias, cruzar fronteras, Santiago de Chile: Cuarto Propio, pp. 13-35.

GIRARD, Rene (1982). La violencia y lo sagrado, Barcelona: Anagrama.

Glantz, Margo, Ed. (1994). La Malinche, sus padres y sus hijos, México: Taurus.

Glantz, Margo (2006). «Doña Marina y el Capitán Malinche». Alicante: Biblioteca Virtual Miguel de Cervantes. Disponible en: http://www.cervantesvirtual.com/ nd/ark:/59851/bmckw5s7 (Fecha de consulta: 21/06/20).

Glantz, Margo (1995). «Las hijas de la Malinche» en Kohut Karl (coord.). Literatura mexicana hoy: del 68 al ocaso de la revolución, pp. 121-129. Disponible en Biblioteca Virtual Miguel de Cervantes: http://www.cervantesvirtual.com/obra-visor/ las-hijas-de-la-malinche--0/html/4b61637f-d0ff-4dc9-85e7-f153ba002088_4. html\#I_0_(Fecha de consulta: 08/06/20).

González Hernández, Cristina (2002). Doña Marina (La Malinche) y la formación de la identidad mexicana. Madrid: Ediciones Encuentro.

Graves, Robert y Raphael PAtai (1986). Los mitos hebreos, Madrid: Alianza.

GRILlo, Rosa María (2011). «El mito de un nombre: Malinche, Malinalli, Malintzin» en Mitologías Hoy. Revista de pensamiento, crítica y estudios literarios latinoamericanos, $\mathrm{N}^{\circ} 4$, pp. 15-26. Monográfico «Fundaciones, cosmogonías y personajes. Mito prehispánico en literaturas latinoamericanas, M. Zabalgoitia Herrera (ed.).

HeINRICH, Johann (1975). El arte y el hombre, Barcelona: Planeta.

Hoppe Navarro, Marcia (2011). «El mito de la Malinche en la obra reciente de escritoras latinoamericanas», en Mitologías Hoy. Revista de pensamiento, crítica y estudios literarios latinoamericanos, $\mathrm{N}^{\circ} 4$, pp. 8-19. Monográfico «Fundaciones, cosmogonías y personajes. Mito prehispánico en literaturas latinoamericanas», M. Zabalgoitia Herrera (ed.).

Karttunen, Frances (1997). «Rethinking Malinche», en Schroeder Susan, Stephanie Wood y Robert HasketT (eds.), Indian Women of Early Mexico, Norman: University of Oklahoma Press, pp. 291-312.

LAmAs, Marta (s.f.). «Las nietas de la Malinche. Una lectura feminista de El laberinto de la soledad», en ZonaPaz. Disponible en: https:/ /zonaoctaviopaz.com/detalle_ conversacion/334/las-nietas-de-la-malinche-una-lectura-feminista-de-el-laberinto-de-la-soledad (Fecha de consulta: 08/06/20)

LeONELLI, Elisabetta (1998). Más allá de los labios, Barcelona: Noguer.

LERNER, Gerda (1990). La creación del patriarcado, Barcelona: Crítica.

López de Gómara, Francisco (1979). La Conquista de México. Madrid: Historia 16, edición de José Luis de Rojas.

Martos García, Alberto y Aitana (2015). «Nuevas lecturas de La Llorona: Imaginarios, identidad y discurso parabólico» en Universum, vol. 30, N², pp. 179-195. 
MARx, Karl (2013) [1846]. Manuscritos, Madrid: Alianza Editorial.

Messinger, Sandra (1991). La Malinche in the Mexican Literature, From History to Myth, Austin: University of Texas Press.

Messinger, Sandra (1997). «La Malinche, historia y leyenda de 'La única mujer importante durante la conquista de México'», en JaramiLlo, María Mercedes y Betty Ossorio (eds.), Las desobedientes. Mujeres de nuestra América, Santafé de Bogotá: Panamericana, pp. 89-105.

Moreno, Amparo, (1998). La otra política de Aristóteles, Barcelona: Icaria.

Nuñez Becerra, Fernanda (2019). La Malinche: De la Historia al Mito, México: Secretaría de Cultura, Instituto Nacional de Antropología e Historia.

PALERM, Ángel (1949). Sobre las relaciones poligámicas entre indígenas y españoles durante la conquista de México, y sobre algunos de sus antecedentes en España, México: Editorial Jus 3.

PAz, Octavio (1950). «Los hijos de la Malinche» en El laberinto de la soledad. México: Fondo de Cultura Económica, 1981, pp. 27-36.

PAz, Octavio (1987). «El peregrino en su patria» en México en la obra de Octavio Paz, México: Fondo de Cultura Económica, t. 1.

Perrot, Michelle y Georges Duby (eds.) (1992). Historia de las mujeres, tomo II, Madrid: Taurus.

Posada Kubissa, Luisa (2017). «Sobre Bourdieu, el habitus y la dominación masculina: tres apuntes» en Revista de Filosofía, vol. 73, pp. 251-257.

Real Academia Española, Diccionario de la lengua española, 23. a ed., 2014 [versión 23.3 en línea]. Disponible en: https: / / dle.rae.es (Fecha de consulta: 27/6/20).

Roldan Rueda, Natalia (2012). Maldición de Malinche. Visiones y reivindicaciones de la Malinche en la obra de Octavio Paz, Carlos Fuentes y Rosario Castellanos, tesis de maestría en literatura, Facultad de Ciencias Sociales, Pontificia Universidad Javeriana.

RouQuie, Alain (1989). Extremo Occidente, Introducción a América Latina, México/Buenos Aires: Siglo XXI Editores.

Spinoso Arcocha, Rosa María (2012). «Nación, mito y control social en México. La Malinche y el proceso de construcción de una antiheroína nacional» en Alcores: revista de historia contemporánea, $\mathrm{N}^{\circ} 13$, pp. 103-121.

TATE, Julee (2019). «Dueling Portrayals of La Malinche in Twenty-First Century Mexican Historical Fiction» en Letras Hispanas, vol. 15, pp. 38-53.

TATE, Julee (2017). «La Malinche: The Shifting Legacy of a Transcultural Icon» en The Latin Americanist, vol. 61, N¹, pp. 81-92.

Todorov, Tzvetan (1987). La conquista de América. El problema del otro, México: Siglo XXI Editores.

Zinam, Oleg e Ida Molina (1991). «The Tyranny of the Myth: Doña Marina and The Chicano Search for Ethnic Identity» en The Mankind Quarterly, vol. 32, Nº1, pp. 3-18.

Recibido el 30 de junio de 2020

Aceptado el 1 de junio de 2021 BIBLID [1132-8231 (2021): 277-289] 